\title{
Traditional knowledge affects soil management ability of smallholder farmers in marginal areas
}

\author{
Martina Occelli ${ }^{1}$ - Alberto Mantino ${ }^{2}$ - Giorgio Ragaglini ${ }^{2} \cdot$ Matteo Dell'Acqua $^{3}$ - Carlo Fadda ${ }^{4}$ Mario Enrico Pè ${ }^{3}$. \\ Alessandro Nuvolari ${ }^{1}$
}

Accepted: 18 November 2020 / Published online: 11 January 2021

(C) The Author(s) 2020

\begin{abstract}
Soil fertility is key to sustainable intensification of agriculture and food security in sub-Saharan Africa. However, when soil nutrients are not adequately managed, smallholder farming practices slowly erode soils to almost inert systems. This case study contributes to the understanding of such failures in marginal areas. We integrate agronomic and social sciences approaches to explore links between smallholder households' farming knowledge and soil fertility in an ethnopedological perspective. We interview 280 smallholder households in two areas of the Ethiopian highlands, while collecting measures of 11 soil parameters at their main field. By analyzing soil compositions at tested households, we identify a novel measure of soil management ability, which provides an effective empirical characterization of the soil managing capacity of a household. Regression analysis is used to evaluate the effects of household knowledge on the soil management ability derived from laboratory analysis. Results highlight the complexity of knowledge transmission in low-input remote areas. We are able to disentangle a home learning and a social learning dimension of the household knowledge and appraise how they can result in virtuous and vicious cycles of soil management ability. We show that higher soil management ability is associated with farmers relying to a great extent on farming knowledge acquired within the household, as a result of practices slowly elaborated over the years. Conversely, lower soil management ability is linked to households valuing substantially farming knowledge acquired through neighbors and social gatherings. The present study is the first to formulate the concept of soil management ability and to investigate the effects of the presence and the types of farming knowledge on the soil management ability of smallholder farmers in remote areas. We show that farming knowledge has a primary role on soil fertility and we advise its consideration in agricultural development policies.
\end{abstract}

Keywords Soil management · Soil fertility $\cdot$ Smallholder farming system $\cdot$ Local food systems $\cdot$ Cropping system $\cdot$ Household knowledge $\cdot$ Ethnopedology $\cdot$ Ethiopian highlands

\section{Introduction}

Soil is a critical element for a resilient and sustainable agriculture (Nkonya et al. 2016); the healthiest the soil, the healthiest and

Martina Occelli

m.occelli@santannapisa.it

1 Institute of Economics \& EMbeDS, Sant'Anna School of Advanced Studies, Pisa, Italy

2 Institute of Life Sciences, Sant'Anna School of Advanced Studies, Pisa, Italy

3 Institute of Life Sciences \& EMbeDS, Sant'Anna School of Advanced Studies, Pisa, Italy

4 Alliance of Bioversity and CIAT, Nairobi, Kenya more abundant the supply of food (FAO 2015). The climatic and social challenges set forward by the Anthropocene era compel to address global food efforts toward the sustainable intensification of existing smallholder farming systems (Waters et al. 2016); half of the current food production in hotspot regions depends on local transgressions of soil macronutrients' boundaries, which calls for a more efficient management of agricultural inputs. In pursuing this goal, agricultural literature on food security put soil at the center of the discussion (Gerten et al. 2020). Preserving soil fertility is a key task especially for the heterogeneous smallholder farmers in sub-Saharan Africa, where four soil degradation phenomena are recognized: water erosion, wind erosion, deterioration of physical properties, and nutrient depletion generated by soil fertility degradation (Tittonell and Giller 2013).

Biophysical elements as well as farmers' decisions affect soil characteristics: indeed, different studies have been 
analyzing the issue of soil fertility degradation among smallholder farmers, showing that it is not solely the result of agronomic factors but also of socio-economic characteristics of the farmer (Sanchez 2002). The maintenance of a fertile soil implies managing the land in a sustainable way, with the existence of a strong relationship between soil management techniques and soil nutrients' availability (Tittonell et al. 2005). Suboptimal soil management choices depict an array of inefficient management practices, which tend to exploit soil macronutrients without an adequate replacement of resources to ensure soil fertility. These suboptimal practices have been attributed primarily to lack of farm-level income, limited access to fertilizers, and households' vulnerability (Ojiem et al. 2006; Vanlauwe et al. 2015). However, while these are surely determinant factors, they can hardly fully explain soil fertility gradients in marginal areas, such as the highland ecosystems, where isolation, low agricultural productivity, and water scarcity make farmers' set of economic possibilities similar. For example, in the highland regions of Amhara and Tigray where this study focuses, farmers do show comparable incomes both in terms of energy yield and off-farm activities; furthermore, they are endowed with a similar set of fertilizers, since their market price is fixed by the government and distribution is assigned to extension workers. Despite these similarities, farmers' management choices impact soils evidently (Altieri 2002) and deficiencies of soil nutrients are highly diversified among households' plots (Vanlauwe et al. 2007). Numerous are the studies linking cultural, behavioral, and social characteristics of farmers with soil deterioration issues (see, for a review, Wuepper 2020; Dessart et al. 2019). In this work, the authors focus on the role of farming knowledge at the household level. Farming knowledge has been advocated as an enabler of food security, through the utilization of local resource knowledge for ensuring a higher yield (Blauert and Zadek 1998). The goal is to screen three different dimensions of farming knowledge previously identified by the literature: firstly, a dimension of characterization and share of knowledge inside the household (Noltze et al. 2012); secondly, a dimension of characterization and share of knowledge among peers (Conley and Udry 2001; Bandiera and Rasul 2006); and lastly, formal training and education (Chowa et al. 2013; Kerr et al. 2019). The target is to capture the effects of each single dimension, in order to provide a comprehensive perspective on farming knowledge dynamics. Indeed, a mosaic of managerial practices for soil fertility conservation stems from the farming knowledge of smallholder farmers in marginal areas (Flores 1989), but few evidences have been collected on soil fertility discrepancies and farming knowledge characteristics.

In the areas considered by this study, smallholder farmers possess a rainbow of soil managerial techniques, which range from refined methodologies to understand when and how fertilizers should be employed, to detailed instructions on the right plowing time; despite evidences of fertility gradients among smallholder farmers, to our knowledge, no other research has focused on the connections between fertility differences and farmers' knowledge in marginal areas like Amhara and Tigray. We hypothesize that in these marginal areas, smallholder farmers able to preserve soil fertility demonstrate a higher management ability, possibly driven by access to a specific set of knowledge.

Relying on advanced ethnopedological approaches, this study combines 280 detailed household surveys with as many thorough physio-chemical analyses of topsoil samples from household's main fields. From this joint perspective, the new interdisciplinary concept of soil management ability is formulated, which conceptualizes the household's ability of managing the soil effectively with respect to the other farmers in the same region. It is a measure of households' management ability, and not individual farmers' ability, and it suggests relative discrepancies of management abilities among neighboring households in the same region, rather than conveying an absolute measure. The soil management ability is calculated stemming from the content of total nitrogen $(\mathrm{N})$, phosphorus $(\mathrm{P})$, and potassium $(\mathrm{K})$ in the soil, which suggest among the smallholder farmers in the villages those capable of managing the soil fertility more effectively (Öborn et al. 2005); this is especially true in subsistence, low-input rainfed farming systems as those analyzed in this work. The objective is to understand how much of long-term invariant components of the soil (e.g., pH, soil texture, and parameters alike) can explain the total variability in the three short-term variant managerial outcomes ( $\mathrm{P}, \mathrm{N}$, and $\mathrm{K})$. What remains to be explained, the residual, captures the soil management ability at household level.

As underlined, the concept of soil management ability encompasses the capacity of a smallholder household to manage effectively the soil: in a low-input environment, this entails not simply the application of the right quantity and type of fertilizers but also a group of practices (such as the right timing at which the fertilizer should be given, the correct management of manure, and the proper crop rotation scheme) which are performed effectively and therefore are able to guarantee adequate soil fertility. The notion of soil management ability departs from the dilemma of merging traditional soil management techniques and agronomic studies (predominant in works such as Mairura et al. 2007), prioritizing the creation of a relative measure of soil fertility performance at the household level based on macronutrients' contents (N, P, and $\mathrm{K}$ ). Despite its importance, farmers' soil knowledge, being it traditional or modern, has hardly being reflected in soil science research (Yaalon and Berkowicz 1997). Strategies to maintain soil fertility and quality have been developed traditionally by farmers: farming strategies mobilize an accurate knowledge of the micro-local soil conditions to select a variety of adapted crop associations (Fujisaka et al. 1996). For example, color changes in the topsoil are used to monitor the fertility status and for early identification of potential productivity decline 
(Barrera-Bassols and Zinck 2003). In this perspective, household's farming knowledge refers to the process of knowledge accumulation which leads to a certain degree of soil management ability for each smallholder farmer; it encompasses soil managerial notions as well as acquired information on farm resources maintenance and diversification (Laekemariam et al. 2018). The notion that farmers do possess a soil management ability is not new: precedent ethnopedological works such as the one of Barrios and Trejo (2003), Barrios et al. (2006), Richelle et al. (2018), Furbee (1989), Tabor (1990), and Mairura et al. (2007) assess extensively the potential for an integrated farmers-scientists approach when it comes to soil management. Pawluk et al. (1992) stress the existence of a cultural aspect of the subsistence production, stating that understanding the knowledge system behind traditional people's management of natural resources is not simply useful, but indeed necessary to address agricultural productivity.

In line with the mentioned literature, we hypothesize that the leading force behind different soil management abilities is not the set of economic possibilities but rather the set of knowledge a household possess. We discuss the existence of three dimensions of farming knowledge at the household level: (i) home learning, (ii) social learning, and (iii) education. Finally, we test if the predominance of one dimension of household knowledge affects differently soil management ability at the household level.

\section{Material and methods}

\subsection{Study area}

The study has been conducted in two areas of Ethiopia: North Wollo in the Amhara region, hereafter labeled Amhara-NW, and Central in Tigray region, hereafter labeled Tigray-C. Both sites are situated in the highland ecosystem, in a range between 2430 and $3240 \mathrm{~m}$ above the sea level. Respondents in Amhara lives between 2443 and $3240 \mathrm{~m}$ above sea level; their homesteads range between $11^{\circ} 34^{\prime} 12.72^{\prime \prime} \mathrm{N}$ and $11^{\circ} 49^{\prime} 59.7^{\prime \prime}$ $\mathrm{N}$ of latitude and between $38^{\circ} 1^{\prime} 43.82^{\prime \prime} \mathrm{E}$ and $39^{\circ} 1^{\prime} 43.82^{\prime \prime} \mathrm{E}$ of longitude. The selected study area in Tigray spans from a latitude of $13^{\circ} 33^{\prime} 33.08^{\prime \prime} \mathrm{N}$ to $13^{\circ} 39^{\prime} 57.24^{\prime \prime} \mathrm{N}$, while the longitude is between $39^{\circ} 6^{\prime} 54^{\prime \prime} \mathrm{E}$ and $39^{\circ} 11^{\prime} 59.57^{\prime \prime} \mathrm{E}$. Farmers in the area live between 2430 and $2679 \mathrm{~m}$ above the sea level.

The regions are in the sub-tropic climatic zone, with one main rainy season (meher) in summer, between June and August, and a second shorter period of occasional rainfalls (belg) from February to May. The study sites are marginal areas in the highland zones of Amhara and Tigray and are representative of low-intensive cereal cultivation regions, especially focused on harvesting wheat, barley, and teff (Kidane et al. 2017). Agriculture and livestock are still the two main sources of living, characterized by low-input soil tillage technology and absence of irrigation; ox-plowing mechanism is ubiquitously used and cropping systems are mainly rainfed; furthermore, animal feeding is based on crop residues. In such remote areas, the complexity of soil fertility management calls for an active role of smallholder farmers (Mowo et al. 2006).

In these study sites, a wide variability in the regional drivers of agricultural systems has resulted in variegated land use and soil management practices (Table 1, Fig. 1).

The investigated regions differ by several pedoclimatic aspects: in particular, total annual rainfall, annual mean temperature, and average altitude. The joint combination of these characteristics determines the existence of two different agroecosystems: in Amhara, the cropping system has two growing seasons in the same year, while Tigray presents just one. Regarding socio-economic characteristics, the two locations share religion (Christian Copti) but vary for language spoken: Amharic is spoken in Amhara-NW and Tigrinya in Tigray-C. In both sites, farmers' livelihood is based on subsistence agriculture and livestock. The low-input rainfed type of agriculture practiced does not allow the cultivation of water-intensive crops; therefore, farmers' diet is restricted to legumes and cereals. Nonetheless, agrobiodiversity is highly present and each household harvests a range between two and seven crops (among others, predominant are barley, wheat, teff, field pea, and chickpea).

The majority of the households surveyed are male headed, with the head of the household taking the agricultural decisions. In Amhara-NW, on average, a household has 5.3 components (min. 1 and max. 9) and the average SAU (Surface of Arable Unit) is 1.2 ha. In Tigray-C, numbers differ slightly: household size floats around 5.5 members (min. 1 and max. 10 ), while the average SAU of 0.28 ha is considerably lower than Amhara-NW. In both regions, smallholder farmers tend to settle permanently in the area: $62 \%$ household respondents in Amhara-NW declare living in the same homestead for more than 10 years, and of the remaining group, 24\% has been living in the same homestead for more than 50 years. In Tigray-C, $60 \%$ is the percentage of households permanently living in the village for more than 10 years and $33 \%$ is the amount of those living in the same homestead for more than 50 years. Regarding agricultural management practices, virtually all households (98\% in Amhara-NW and 97\% in TigrayC) use own labor for mastering the land. Shared labor is a used practice, but it is not endemic: indeed, it is practiced by $27 \%$ of the households in Amhara-NW and 34\% in Tigray-C.

Among all animals, oxen are the most valuable given the persistent presence of ox-plowing technology in the area. Crop rotation is diffuse in both regions, but often it is merely restricted to cereal crop rotation. Cash crops are absent, with the exception of eucalyptus; this tree is a fast-growing crop, tolerant to low soil fertility and prolonged periods of moisture stress (Jagger and Pender, 2003). In northern Ethiopia, 
Table 1 Biophysical, socioeconomic, and agronomic description of the two study sites

\begin{tabular}{|c|c|c|c|}
\hline \multirow[t]{2}{*}{ Variable } & \multirow[t]{2}{*}{ Unit } & \multicolumn{2}{|l|}{ Sub-location } \\
\hline & & Amhara-NW & Tigray-C \\
\hline \multicolumn{4}{|l|}{ Biophysical characteristics } \\
\hline Average altitude & $\mathrm{m}$ & 2880 & 2516 \\
\hline Annual mean temperature & ${ }^{\circ} \mathrm{C}$ & 18.4 & 21.5 \\
\hline Total annual rainfall & $\mathrm{mm}$ & 866 & 648 \\
\hline Köpper-Geiger classification & & $\begin{array}{l}\text { Temperate, dry winter, } \\
\text { warm summer }(\mathrm{Cwb})\end{array}$ & $\begin{array}{l}\text { Temperate, dry winter, } \\
\text { warm summer }(\mathrm{Cwb})\end{array}$ \\
\hline \multicolumn{4}{|l|}{ Agronomic characteristics } \\
\hline Main crop harvested & & Wheat & Wheat \\
\hline $\begin{array}{l}\text { Majority of improved varieties } \\
\text { among planted crop }\end{array}$ & & No & Yes \\
\hline Cropping season in 1 year & Number & 2 & 1 \\
\hline \multicolumn{4}{|l|}{ Socio-economic indicators } \\
\hline Average plot size at farm level & ha & 0.75 & 0.28 \\
\hline Average population age & Year & 25.44 & 24.97 \\
\hline Average education level & Year & $<5$ years of schooling & $<5$ years of schooling \\
\hline Household size & Members & 5.34 & 5.58 \\
\hline $\begin{array}{l}\text { Average time households have } \\
\text { lived in that same village }\end{array}$ & Year & $\begin{array}{l}\text { More than } 10 \text { but less than } \\
50 \text { years }\end{array}$ & $\begin{array}{l}\text { More than } 10 \text { but less than } \\
50 \text { years }\end{array}$ \\
\hline Cultural group & & Amharic & Tigrinya \\
\hline Language & & Amharic & Tigrinya \\
\hline
\end{tabular}

Fig. 1 Representation of the study area. Panel a shows the location of the two study areas in Ethiopia: 12 villages are located in Amhara (upper central part of Ethiopia) in the county of North Wollo and 12 villages are located in Tigray (northern part of Ethiopia), in the county of Central Tigray. In these two areas, agriculture is of a low-input, rainfed type and it involves the utilization of the ox-plowing technology by smallholder farmers, as stylized by panel $\mathbf{b}$. Panel $\mathbf{c}$ pictures the marginal landscape in which smallholder farmers of the study operate, characterized by small plot and steep slopes. Lastly, panel d depicts a key part of the field work necessary for this study, the soil sampling
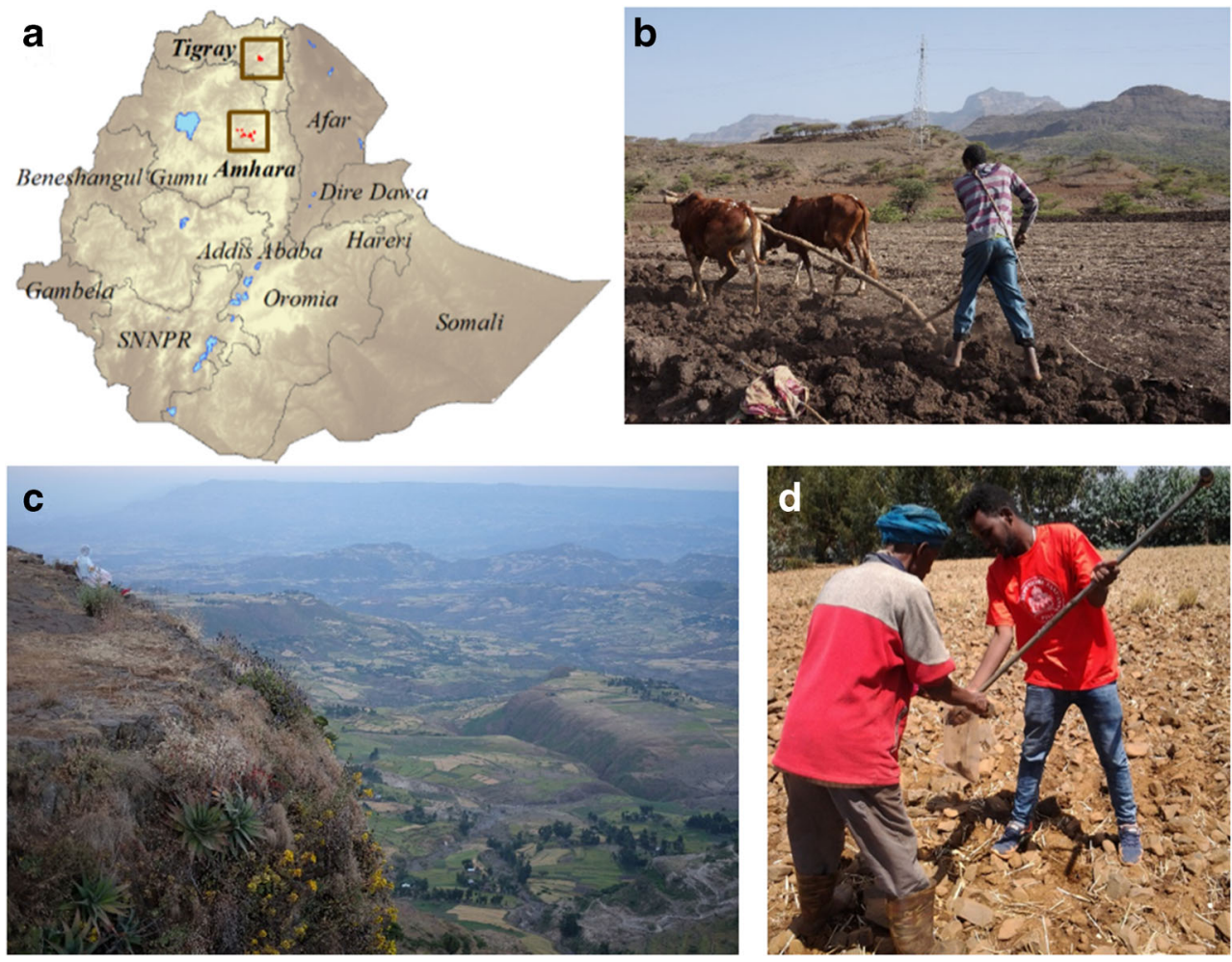
eucalyptus is the most commonly observed tree species and it serves manifold purposes. However, its ecological footprint, especially on the soil, is a source of concern: even though planting trees can return nutrients such as total nitrogen and exchangeable potassium to the soil, one of the most cited criticism associated with eucalyptus is depletion of soil nutrients (Jagger and Pender, 2003). Smallholder farmers involved in the study have often reported issues of soil fertility depletion in connection with eucalyptus plantations. For these reasons, eucalyptus is inserted in the regression analysis relating soil management ability and household's farming knowledge as control on resource availability at the household level.

Agricultural decisions within the household are usually taken by the household head; participants in both study areas declare to rely extensively on the farming knowledge acquired inside the homestead, suggesting a mechanism of learning from past generations to new entrants in the family. In a complementary fashion, participation in the agricultural communitarian life is a milestone for the households in our study, and it involves attendance in formal meetings (agricultural trainings or seed bank activities) and informal agricultural gatherings. Formal trainings are usually provided according to a participatory extension system, which takes place within a complex bureaucratic structure that often involves top-down approaches. In both regions, agricultural extension workers and formal trainings are the backbone for the actuation of rural development policies; nonetheless, they frequently fail due to a combination of one or more of the following reasons: large number of potential training recipients, geographic dispersion, infrastructure constraints, and diversification of agroecological conditions (Berhane et al. 2018). In a complementary manner, informal gatherings represent an array of institutions traditionally active in both study areas: among them, worth mentioning are $i d i r$ (insurance institution in case of extreme events), iqub (financial institution of mutual help), debo (labor-sharing institutions among neighbors), and dado (laborsharing institution during peak harvesting times) (Negera et al. 2019).

\subsection{Sampling and data acquisition}

Twenty-four villages were selected in the two regions, using an approach designed to maximize the representation of the entire territorial extension (with the support of GIS). The resulting coverage includes two counties (or woreda), Amhara-NW and Tigray-C; 12 villages (or kebele) for each county, representing $40 \%$ of the villages present in each area; and 12 households in each village, representing $5 \%$ of the entire household population living permanently in each village. Combined, the study selected randomly 288 households (144 located per county). The list of villages surveyed in Amhara-NW is the following: Aymat, Agrit, Akat, Taja, Weketa, Timtimat, Gashena, Hamusit Silasie, Workaye,
Hana mekuat, Yewotet, Amba Yedogit. In Tigray-C, the 12 villages involved are Hadnet, Adi Kuenti, Resetu, Endamariam Awleo, Guderbo, Hoseya, Melfa, Bowak, Adawro, May sedri, Meda golat, Golat.

Of the randomly chosen 144 households in each region, extension workers were able to locate precisely 141 households in Amhara-NW (97\%) and 139 (96\%) households in Tigray-C. Each household has been interviewed with an extensive survey, created to allow for quantitative and qualitative data collection; surveys have been performed with tablets running ODK program. The field work was iterated in the months of February and March 2019, before the ploughing season, so as to gain the full attention of the farmers and interfere the least in their work. For the data and soil collection, two teams of 12 enumerators each have been employed, selected, and trained. Enumerators needed to have English knowledge, as well as some basic agronomic experience, in an effort to collect correctly the soil samples and minimize the collector bias effect in the data. For Amhara-NW, the 12 enumerators were actively working at the Sirinka Centre of the Amhara Agricultural Research Institute while in Tigray-C, enumerators were researchers in the Agroecology Department at the Mek'ele University. Focus groups and key informant surveys (among others, with local chiefs and agricultural extension workers) performed during the year 2017 and 2018 are considered preparatory to enrich the narration of the mechanisms described.

Along with the survey data, the team collected one topsoil sample (0-15-cm depth) from each household's main field, for a total of 280 soil samples in the two regions. GPS points have been recorded both at the household home and at the household main plot, where the soil sample has been taken. Physiochemical analyses have been conducted in Debre Zeit (Ethiopia) for the following 11 parameters: $\mathrm{pH}-\mathrm{H}_{2} \mathrm{O}$; texture, electric conductibility, available phosphorus, exchangeable potassium, total nitrogen, organic carbon, organic matter, $\mathrm{CaCO}_{3}$, and bulk density.

\subsection{Data analysis}

\subsubsection{Analysis of questionnaire data}

A household questionnaire was constructed in order to capture socio-economic as well as agronomic characteristics of the households, following the standard for survey development set by the Living Standard Measurement Survey of the World Bank and the Abdul Latif Jameel Poverty Action Lab. The survey contains questions about demographic characteristics of the farmer, agronomic practices, microclimatic managerial choices, farming beliefs, and knowledge. In the latter group, a subset of 5 questions out of 10 was meant to capture first-order belief (FOB) about farming knowledge of the household's head (i.e., the decision-maker when it comes 
to agricultural affairs). The goal was to screen three different dimensions of farming knowledge previously identified by the literature: (i) accumulation of farming knowledge inside the household, (ii) acquisition of farming knowledge among peers and between households, and lastly (iii) farming knowledge obtained in formal trainings and education. The target was to capture the effects of each single dimension, in order to provide a comprehensive perspective on farming knowledge dynamics.

Following a theory-driven approach based on previously identified literature (as cited in Section 1), we formalized household's farming knowledge as follows: (i) home learning, grouping those questions referring to farming practices learnt inside the household; (ii) social learning, gathering impressions on the mechanisms of social imitation in the village; and (iii) education, iconizing general knowledge acquired in school. Each of these three dimensions has been represented by a set of questions in the survey:

\section{(i) Home learning}

(a) q.1 "It has happened in my household to try new crops, new combinations and/or new techniques related to farming which were unknown to my friends and neighbors" ( $\mathrm{T} / \mathrm{F}$ answer)

(b) q.2 "I would introduce/abandon a new farming technique if a member of my family suggests so". (T/F answer)

(ii) Social learning

(a) q.1 "I am open to farming advices coming from outside my household" ( $\mathrm{T} / \mathrm{F}$ answer)

(b) q.2 "I would introduce/abandon a new crop if a member of my village suggests so". (T/F answer)

\section{(iii) Education}

(a) q.1 "What's your education level?".

The key variables measuring the home and social learning dimensions were merged utilizing a weighted sum: being two dummies, the final value of local and social learning assumed value 0 (low) if neither of the two dummies were positive, assumed value 1 (middle) if only one of the two was positive, and assumed value 2 (high) if both of them were positive. For the dimension of formal education, only the declaration of school attainment has been included in the analysis; this is represented by a categorical variable between 1 (illiterate) and 4 (attended more than 10 years of schooling), with 5 being literate but with no formal education. The set of knowledgerelated questions was analyzed through a principal component analysis (PCA), so as to explore if the theory-based construction would find evidences in a data-driven approach; other information contained in the questionnaires (e.g., off-farm income, age, and gender) were used as controls in the subsequent statistical analysis.

\subsection{Statistical analysis}

The statistical analysis was conducted in two steps: firstly, we computed a new measure of the soil managerial capacity of farmers, called farmer's soil management ability; secondly, the three knowledge dimensions previously identified were regressed against the soil management ability of each household, utilizing three different models.

\subsubsection{Computation of the soil management ability at household level}

The soil management ability (SMA) is calculated discretizing for the content of total nitrogen (TN), available phosphorus $(\mathrm{P})$, and exchangeable potassium $(\mathrm{K})$ detected from the soil analysis of each farmer's main field, after controlling for region and for pedological characteristics of the terrain: i.e., soil texture, organic matter content $(\mathrm{OM}), \mathrm{pH}$, altitude, total carbonate (TC), electric conductibility (EC), cations exchange capacity (CEC), and carbon-nitrogen ratio $(\mathrm{CN})$.

The content of TN, $\mathrm{P}$, and $\mathrm{K}$ can suggest among the smallholder farmers in the villages those capable of managing the soil fertility more effectively (Öborn et al. 2005); this is especially true in subsistence, low-input rainfed farming systems as those analyzed in this work. Indeed, the information that these three macronutrients can convey are multiple: (i) TN, P, and $\mathrm{K}$ are considered major nutrient elements and are essential for plants and animals (Öborn et al. 2005); (ii) they are responsible for crucial physiological processes of the crops, such as photosynthesis, stimulation of early growth, transportation of water, and drought resilience (Tripathi et al. 2014); (iii) $\mathrm{P}$ availability, in particular, is extensively limited, and given the current rate of depletion of available phosphorus reserves, this nutrient will become a major limiting crop yield factor by 2050 (Balemi and Negisho 2012); (iv) they have been identified by the several sub-Saharan agricultural agencies (ATA 2013) as the main deficiencies in most agroecosystems of the continent.

Data were aggregated into a stepwise regression model with bidirectional elimination, where TN, $\mathrm{P}$, and $\mathrm{K}$ constituted the three dependent variables. The pedological parameters previously listed were utilized as predictors, following the FAO Global Soil Partnership, which fosters the exploration of links between socio-economic and environmental variables utilizing regressions in the context of the Digital Soil Mapping Initiative (Meeting in Teheran, January 2018) (Lombardo et al. 2018).

In this basic model, each of the three outcome variables was regressed against a common set of pedological predictors. They were $\mathrm{OM}, \mathrm{pH}-\mathrm{H}_{2} \mathrm{O}$, altitude, presence of clay, sum 
between the presence of clay and the presence of silt (inserted for investing the compaction level of the soil, which affects nutrients presence by decreasing the rate of decomposition of soil organic matter and subsequent release of nutrients (USDA-NRCS 1996)), $\mathrm{CaCo}_{3}, \mathrm{EC}, \mathrm{CEC}$, and CN.

The full model specification at the farmer level is the following:

$$
\begin{aligned}
& T N_{i k} \sim \alpha+\beta_{i j k} X_{i j k}+\varepsilon_{i} \\
& P_{i k} \sim \alpha+\beta_{i j k} X_{i j k}+\varepsilon_{i} \\
& K_{i k} \sim \alpha+\beta_{i j k} X_{i j k}+\varepsilon_{i}
\end{aligned}
$$

With:

$\beta_{i j k}=$ coefficient attached to each $j$ regressors, in each region $k$, for each farmer $i$

$X_{i j k}=$ common set of pedological invariant regressors $j$ for each farmer $i$ in each region $k$

$k=$ study regions (Amhara-NW and Tigray-C)

The residual is the portion of TN, $\mathrm{P}$, and $\mathrm{K}$ not predicted by soil long-term conditions. Therefore, for each farmer $i$ in each region $k$, the predicted value suggests what is the lower (or upper) bound value of that outcome variable (TN, P, or K), given the pedological conditions. The difference between this bound and the actual value measured by the laboratory analysis represents the residual, and it captures the management ability of each farmer $i$ to master the considered macronutrient in the main field's soil. In order to compute a unique farmer's soil management ability score generated by the ability of mastering each macronutrient, we estimated the quantile position for each residual in the specific macronutrient distribution. To every quantile, an increasing value (from 1 for the lower 0 $25 \%$ to 4 for the highest $75-100 \%$ ) was assigned; given the fact that all three macronutrients matter for soil quality, the sum of the quantile ordering values was calculated.

Therefore, the ability of each farmer was framed into a value which goes from a minimum of 3 (if all the three parameters belong to the lower quantile) up to a maximum of 12 (if all the three parameters belong to the highest quantile). This value was called soil management ability of the farmer and it is the crucial outcome variable for the socio-economic analysis.

\subsubsection{COM-Poisson model for regressing household farming knowledge on soil management ability}

Isolating the value of the soil management ability for each household, the possible effects of the knowledge's dimensions were investigated. Utilizing as outcome the soil management ability variable led to the use of the Poisson family of count data model; however, soil management ability data are under- dispersed (and by construction not inflated with zeros, since the minimum value equals 3 ); this was confirmed by the calculation of the index of dispersion (Selby 1965) for both regions, which was equal to 0.63 for Amhara-NW and 0.55 for TigrayC. In the aim of performing an effective but clean and simple econometric exercise, we have opted for utilizing a COM (Conway-Maxwell)-Poisson approach (Winkelmann and Zimmermann 1994). The econometric exercise was performed in R software: the package utilized is \{COMPoissonReg\}. We included controls for resources possessed by the household (levels of on-farm income source converted in $\mathrm{kcal} / \mathrm{ha}$ and prot/ha, presence of off-farm income activities and woodlot) and for characteristics of the household head (age and gender). If additional controls were inserted (household type, labor type, sex ratio, dependency ratio, farm size, amount of tropical livestock units, market distance), regressions' results did not vary.

Subsequently, smallholder farmers belonging to the top (75-100\%) and bottom (0-25\%) quartile of the soil management ability distribution were isolated and introduced in a new logistic regression model as dependent variables. Households in the top quartile of the soil management ability distribution were defined as high soil management ability farmers (HSF), while households in the bottom quartile of the soil management ability distribution were defined as low soil management ability farmers (LSF). Therefore, the full logit model specification at farmer level was the following, for high and low soil farmers, respectively:

$$
\begin{aligned}
& H S F_{i k} \sim \alpha+\beta_{i k} X 1_{i k}+\gamma_{i k} X 2_{i k}+\delta_{i k} X 3_{i k}+\mu_{i j k} Z_{i j k}+\varepsilon_{i} \\
& L S F_{i k} \sim \alpha+\beta_{i k} X 1_{i k}+\gamma_{i k} X 2_{i k}+\delta_{i k} X 3_{i k}+\mu_{i j k} Z_{i j k}+\varepsilon_{i}
\end{aligned}
$$

With:

$\beta_{i k}=$ coefficient for home leaning, in each region $k$, for each farmer $\mathrm{i}$

$X 1, X 2, X 3_{i k}=$ categorical variable for home learning, social learning, and education respectively, for each farmer $i$ in region $k$

$\mu_{i j k}=$ coefficient attached to each $j$ controls, in each region $k$, for each farmer $i$

$Z_{i j k}=$ common set of resource and farmer's level controls $j$ for each farmer $i$ in each region $k$

$k=$ study regions (Amhara-NW and Tigray-C)

The econometric exercise was performed in R software: the package utilized is \{miceadds\}. Errors were clustered at the village level and controls inserted were the same as the COMPoisson regression model.

\subsubsection{OLS regression of household's farming knowledge on soil fertility macronutrients}

Lastly, using a simple OLS (ordinary least square) model, we tested whether the relation identified between 
household farming knowledge and soil management ability held for raw values of soil macronutrients as well. This regression highlighted an absolute measure of the knowledge effect on soil fertility of the main investigated fields; however, this measure was affected by locus-specific physio-chemical factors, which could encompass elements of soil macronutrients' availability not driven by gradients in households' farming knowledge. The development of a soil management ability indicator cleaned this issue, being a relative, rather than an absolute, measure of the contribution of farmers' management ability on managing soil macronutrients' content.

The full model specification at farmer level is the following:

$$
\begin{aligned}
& T N_{i k} \sim \alpha+\beta_{i k} X 1_{i k}+\gamma_{i k} X 2_{i k}+\delta_{i k} X 3_{i k}+\mu_{i j k} Z_{i j k}+\varepsilon_{i} \\
& P_{i k} \sim \alpha+\beta_{i k} X 1_{i k}+\gamma_{i k} X 2_{i k}+\delta_{i k} X 3_{i k}+\mu_{i j k} Z_{i j k}+\varepsilon_{i} \\
& K_{i k} \sim \alpha+\beta_{i k} X 1_{i k}+\gamma_{i k} X 2_{i k}+\delta_{i k} X 3_{i k}+\mu_{i j k} Z_{i j k}+\varepsilon_{i}
\end{aligned}
$$

With:

$\beta_{i k}=$ coefficient for home leaning, in each region $k$, for each farmer $i$

$X 1, X 2, X 3_{i k}=$ categorical variable for home learning, social learning, and education respectively, for each farmer $i$ in region $k$

$\mu_{i j k}=$ coefficient attached to each $j$ controls, in each region $k$, for each farmer $i$

$Z_{i j k}=$ common set of resource and farmer's level controls $j$ for each farmer $i$ in each region $k$

$k=$ study regions (Amhara-NW and Tigray-C)

The regression which involved the raw values of the three macronutrients is represented by an OLS model, performed in $\mathrm{R}$ with the package \{olsrr\}. Controls were inserted for soil texture, OM, and altitude, as the main pedological and environmental influencing factors (Hamiache et al. 2012). Organic matter content played a peculiar role: since many tropical soils are poor in inorganic nutrients, they relied on the recycling of nutrients from soil organic matter to maintain fertility; in this perspective, tests of soil nutrients (such as TN, P, and K) might generate unreliable results (Tiessen et al. 1997).

\section{Results and discussion}

As previously mentioned, the results on household's soil management ability are extracted from a bidirectional stepwise regression model, where the following physio-chemical soil controls are inserted: soil texture, organic matter content, $\mathrm{pH}$, altitude, total carbonate, electric conductibility, cation exchange capacity, and carbon-nitrogen ratio. The model generates in Amhara-NW an adjusted R-square of 0.45, 0.25, and
0.41 for, respectively, TN, P, and K. Similarly, in Tigray-C, the regression registers an adjusted $\mathrm{R}$-square of $0.34,0.45$, and 0.51 . Soil management ability presents an under-dispersed distribution in both regions: indeed, the index of dispersion is 0.63 for Amhara-NW and 0.55 for Tigray-C (Fig. 2a). Despite the proximity of the plots and the marginal nature of the ecosystem, soil management ability is widely diversified among farmers, even within same villages (Fig. $2 b$ and c).

It should be noticed that the residuals of the regressions (and therefore its subsequent combination) might suffer from overestimation, since in the error term also a random measurement error might be included. Arguably, measurement errors are typically of two natures in surveys: (i) either they are driven by enumerators' choices or (ii) they are driven by climate or, more in general, environmental factors. The former error has been minimized by selecting field enumerators with agronomist experience and by accurately training them on the soil and survey data collection before the actual implementation of the work. The physical presence of the principal investigator of the project in all the field workdays served also as a deterrent for inaccurate data collection. The second type of error might be, on the other hand, more problematic to detect: climate and environmental conditions might shape the soil characteristics through a mechanism not related to soil management. Nonetheless, there is no doubt that partially these effects are captured by the pedological characteristics, invariant through time to farmers' actions but not to environmental and climate changes. Moreover, if a change of this nature would occur, this would likely be homogeneous for all farmers in a village given the joint proximity of our observations' location.

\subsection{The dimensions of household's farming knowledge}

In justifying discrepancies in soil management ability, the established theory would look for differences in income or input availability, wealth, and production strategies among smallholder households (Tittonell et al. 2005; Crowley 1997). However, in marginal areas, these factors remain vague in their explicatory power; thus, we focus on the possible role of household's farming knowledge.

Household's farming knowledge has been represented as a composite theory-derived concept, characterized by three complementary dimensions: (i) home learning, (ii) social learning, and (iii) education. The PCA analysis confirms the existence of the three dimensions (Fig. 3a). The first two principal components, describing the relationship among the 5 knowledge-centered questions of the survey, explain around $50 \%$ of the total variance. Looking at the vector representation of the correlation among questions, 3 distinct groups emerge: in particular, the majority of the questions related to mechanisms of within-household knowledge accumulation, or home learning (represented by the $h$ letter), group together in the 

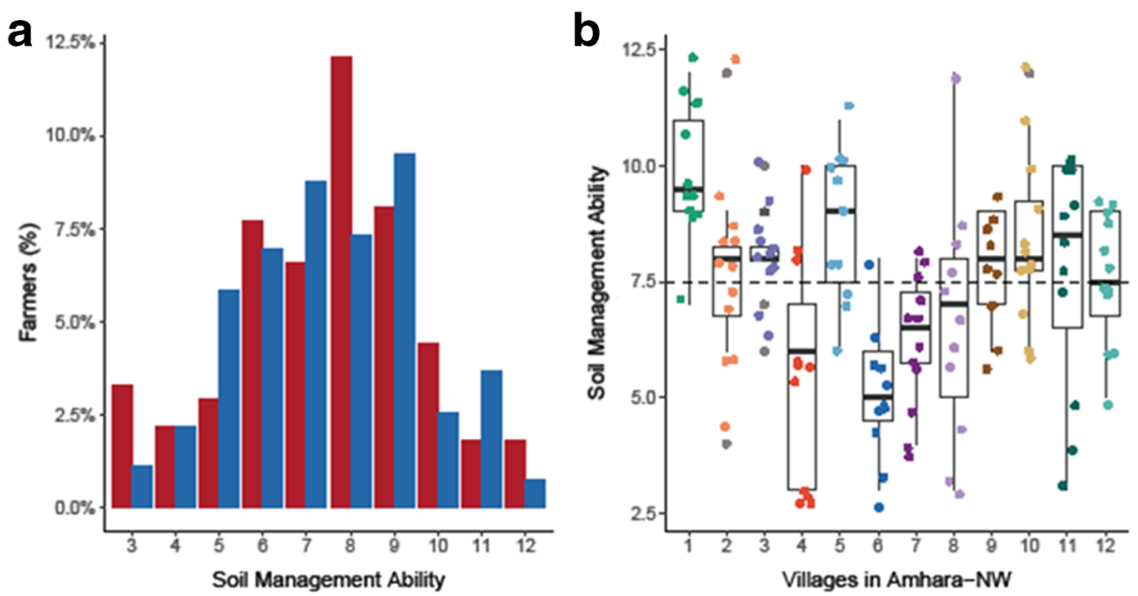

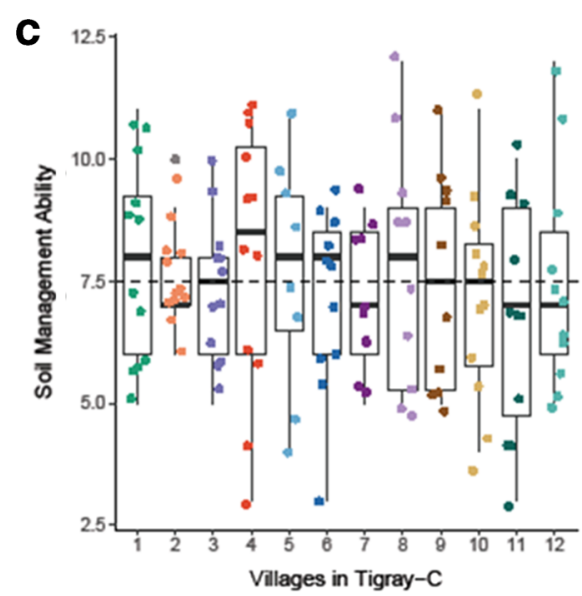

Fig. 2 Farmer's soil management ability in the study areas. Panel a shows the distribution of soil management ability indicator for smallholder farmers in Amhara-NW (red) and Tigray-C areas (blue); panels b and c represent the variability of the soil management ability indicator at the village level for Amhara-NW and Tigray-C. Different colors indicate different villages in each region positive quadrants of the graph, while questions related to mechanisms of between-households knowledge acquisition, or social learning (represented by the $s$ letter), lay in the below-adjacent quadrant of the graph, again almost all grouped together. If correlation is strong within each dimension, the correlation between groups, i.e., between home and social learning, appears almost absent, as the two groups of vectors approach a $90^{\circ}$ angle position. This suggests that these two aspects of the knowledge are actually driven by distinct mechanisms of accumulation and acquisition. Lastly, the education-related question (represented under the acronym of edu) sits in between, showing a positive but not strong correlation with both home and social learning. This finding is indeed quite intuitive, as education contributes to the enhancement of both home and social mechanisms of learning.

A further descriptive analysis suggests that, in both regions, smallholder households attribute generally high value to the acquisition of home and social learning (Fig. 3b and c). More specifically, only 5 villages in Amhara-NW and 3 villages in Tigray-C have farmers declaring of attributing low value to either home or social learning; furthermore, in both regions, high values of social learning are relatively more frequent with respect to high values of home learning. This signals the importance of access to knowledge and of social mechanisms of knowledge acquisition, in accordance with previous literature (Conley and Udry 2001; Bandiera and Rasul 2006). Lastly, it exists a diffuse degree of initial educational attainment, especially in Amhara-NW, even though illiteracy still prevails among respondents.

\subsection{Effect of household's farming knowledge on soil management ability}

The relation between household's farming knowledge and soil management ability is consequently investigated. Results show that household's farming knowledge affects soil management ability gradients among farmers (Table 2).

Utilizing a COM-Poisson regression model for underdispersed count data, the findings support the fact that household's farming knowledge relates significantly with soil management ability. Nonetheless, the direction of the effect depends on the dimension of household's knowledge considered: the relation between home learning and soil management ability is significantly positive $(p<0.10)$, whenever resource level and farmer's level controls are inserted. On the other hand, the relation between the social learning dimension and soil management ability is highly significant $(p<0.05)$ and persistently negative. Furthermore, the relation between education and soil management ability is never significant.

Furthermore, smallholder farmers belonging to the top $(75-100 \%)$ and bottom (0-25\%) quartile of the soil management ability distribution are isolated and introduced in a new logistic regression model, so as to understand how the probability of a smallholder farmer to be in the lowest or highest part of the soil management ability distribution varies. Hereafter, households in the top quartile of the soil management ability distribution are defined as high soil management ability farmers, while households in the bottom quartile of the soil management ability distribution are defined as low soil management ability farmers. Results (Table 2) show that being prone to home learning increases for smallholders the odds of being high soil management ability farmers by 1.8 times $(\exp (0.59))(p<0.01)$. This means that the odds of being a high soil management ability farmer are $80 \%$ higher if the farmer values home learning as opposed to a farmer who does not value home learning. Conversely, being prone to social learning decreases the odds of being a high soil management ability farmer by 0.48 times $(\exp (-0.73))(p<0.01)$. This means that the odds of being a high soil management ability farmer are 

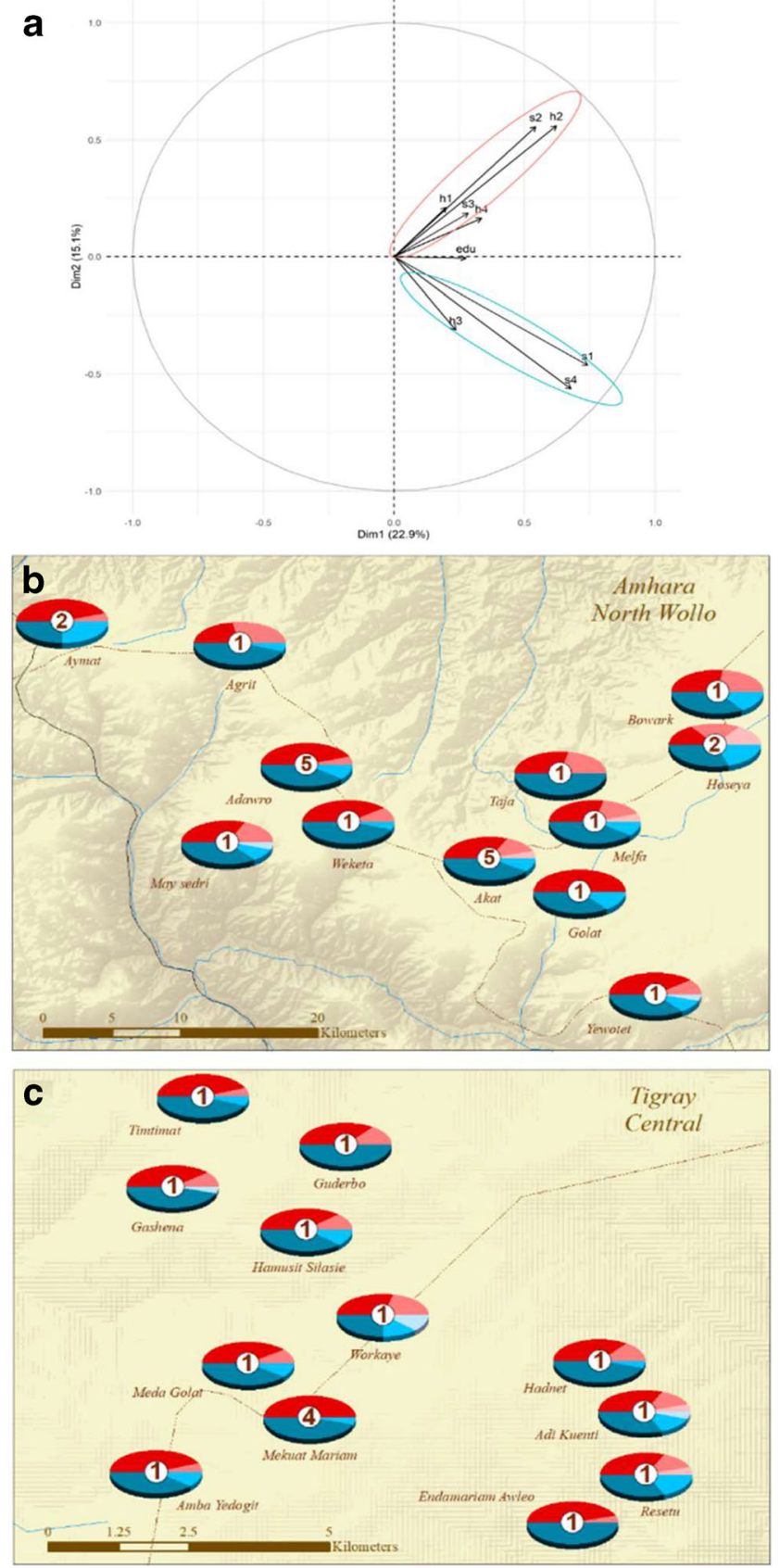

Fig. 3 Dimension of household's farming knowledge. Panel a represents the 3 dimensions of knowledge resulting from the principle component analysis. $\mathrm{H}, \mathrm{S}$, and edu initials refer respectively to home learning, social learning, and education variables. Panels $\mathbf{b}$ and $\mathbf{c}$ capture the spatial distribution of the three dimensions' frequencies in each village, for Amhara-NW (b) and Tigray-C (c). Darker colors signal the presence of higher degree of home (if red) or social (in blue) learning dimension. The number at the center of each pie chart indicates the category of education most common in that specific village: 1 stands for the fact that the majority of the household heads interviewed in that village are illiterate, 2 and 3 represent respectively the majority of household heads who have attended less than 5 years of schooling and between 5 and 10 years of schooling, and 4 depicts household heads with the highest degree of learning, i.e., attendance at school for more than 10 years, while 5 pictures a majority of household heads able to read and write, but not formally educated
$52 \%$ lower if the farmer values social learning as opposed to a farmer who does not value social learning. These effects are significant and robust to the introduction of controls for on-farm and off-farm income resources, as well as smallholder farmers' age and gender.

In a similar fashion, the odds of being a low soil management ability farmer increase by $1.91(\exp (0.65))$ $(p<0.10)$ times if the farmer values social learning knowledge and the effect is significant and robust to controls. This entails that the odds of being a low soil management ability farmer are $91 \%$ higher if the farmer values social learning as opposed to a farmer who does not value social learning. The odds of being a low soil management ability farmer instead do not show a significant relation with the fact that the farmer values home learning knowledge (indeed, the odds ratio decrease by $0.74(\exp (-0.30))$ times but it is not statistically significant). Degree of education is never significant, confirming the results from the COMPoisson model (Table 2).

OLS results linking directly household farming knowledge and raw values of soil fertility (Table 2) confirm the direction of the relation found previously between soil management ability and knowledge for P content: in cases when home learning is valued by the farmer, the content of $\mathrm{P}$ increases significantly by $13.19 \mathrm{mg} \mathrm{kg}^{-1}(p<0.01)$; conversely, when social learning is valued, the relation between the content of $\mathrm{P}$ and social learning is negative, but the coefficient is not significant. Comparable to the results previously listed, education is also never significant.

For the remaining two macronutrients, $\mathrm{TN}$ and $\mathrm{K}$, the direction of the relations is aligned with the one previously identified on soil management ability, but the effect is not statistically significant. However, it comes with no surprise that the content of $\mathrm{P}$ prevails in terms of significance, since, among the three main fertility parameters, $\mathrm{P}$ is the predominant nexus with smallholder farmers' resilience (Jarvie et al. 2015).

These correlation analyses are intuitive in their explicative power, observing that diverse sets of knowledge relate differently with the soil management ability of the households; nonetheless, we cannot impute any causal effects to them, since the model might suffer from omitted variable bias and reverse causality issues. However, our survey data are detailed enough to allow us to control for otherwise confounding factors; in the perspective of strengthening our findings, we have inserted additional controls, beyond those already discussed in Section 2.4.2. They are as follows: (i) economic controls: beyond off-farm income availability and the presence of cash crop (i.e., eucalyptus in case of Amhara and Tigray), we included energy yield obtained from the main plot (in terms of protein content) and the revenue yield of the main plot, derived multiplying the type and quantity of harvested crop with the market 
Table 2 Regression coefficients of soil ability for both study areas

\begin{tabular}{|c|c|c|c|c|c|c|}
\hline & \multicolumn{6}{|l|}{ Dependent variable } \\
\hline & Soil ability & $\begin{array}{l}\text { High soil ability } \\
\text { farmers }\end{array}$ & $\begin{array}{l}\text { Low soil ability } \\
\text { farmers }\end{array}$ & $\mathrm{TN} \mathrm{mg} \mathrm{kg}^{-1}$ & $\mathrm{P} \mathrm{mg} \mathrm{kg}^{-1}$ & $\mathrm{~K} \mathrm{mg} \mathrm{kg}^{-1}$ \\
\hline & $\begin{array}{l}\text { COM-Poisson } \\
\text { model }\end{array}$ & Logit model & Logit model & OLS & OLS & OLS \\
\hline Home learning & $0.11 *(0.061)$ & $0.59 * * *(0.224)$ & $-0.30(0.350)$ & $0.003(0.002)$ & $13.19 * * *(5.25)$ & $58.60(37.87)$ \\
\hline Social learning & $-0.14 * *(0.065)$ & $-0.73 * * *(0.282)$ & $0.65 *(0.363)$ & $-0.001(0.002)$ & $-5.17(5.67)$ & $-34.66(40.90)$ \\
\hline Education & $0.006(0.021)$ & $0.015(0.106)$ & $-0.103(0.111)$ & $-0.0007(0.0007)$ & $-1.08(1.76)$ & $3.11(12.75)$ \\
\hline $\begin{array}{l}\text { Resource-level } \\
\text { controls }\end{array}$ & Yes & Yes & Yes & & & \\
\hline Farmer-level controls & Yes & Yes & Yes & & & \\
\hline $\begin{array}{l}\text { Environmental } \\
\text { controls }\end{array}$ & & & & Yes & Yes & Yes \\
\hline Pedological controls & & & & yes & yes & yes \\
\hline Observations & 273 & 273 & 273 & 273 & 273 & 273 \\
\hline
\end{tabular}

Significance level: $p$ value $<0.01(* * *) ;<0.05(* *) ;<0.10(*)$

In parenthesis for all models: standard error of the mean; logit models have errors clustered at the village level and coefficients expressed in terms of log odds ratio

price for that crop registered in the closest market of the area. These additional economic controls are focused on the main plot of the household, since it is the most important plot on which the soil management ability is calculated. (ii) Extra socio-economic controls have been included as well: beyond household's head gender and age, we have controlled for self-perceived soil fertility of the main plot and self-capacity of the household's head. The former element approximates the capability of the household's head to interpret changes in soil fertility and it controls for a broad understanding that the head possesses on his/her own soil ecosystem. Self-capacity captures instead the self-esteem of the household's head and it is derived from the question "I think I am a good farmer for my lands" (answers on a Likert scale). This helps controlling for attitude toward peers and willingness to accept advice from others. Regional effects are also considered with the inclusion of regional as well as village dummies. These controls for robustness do not change the direction or the significance of the home learning, social learning, and education coefficients.

\subsection{Virtuous and vicious cycles of household's farming knowledge}

Results from the three models state that household's farming knowledge covers a dominant role in explaining differences in soil abilities among smallholder farmers; this finding is robust, no matter the fact of controlling for resource availability and household's characteristics (Table 2). Moreover, when the three dimensions of the household's farming knowledge are disentangled, surprising drifts emerge: home learning is persistently significant and positive across results, showing a virtuous cycle connecting local agricultural knowledge accumulated within the household and the soil management ability of that household. On the contrary, a vicious cycle arises from the social learning mechanism. This puzzling result calls for more insights on the knowledge accumulation processes among the smallholder households in our areas of the study. The in-house transmission of agronomic and rural practices characterizes extensively Ethiopia and, more broadly, subsistence farming systems in highland marginal areas. Indeed, home learning is the pre-existing set of household-specific agricultural knowledge (Noltze et al. 2012) and, as underlined in Section 1, it involves a constant learning from one generation of household members to another. It is therefore not surprising the fact that within-household mechanisms of knowledge accumulation show a positive correlation with the soil management ability of the household himself.

However, social learning's vicious cycle is counterintuitive. Social processes of accumulation of knowledge in marginal areas have been extensively studied by the literature on development and networks (Munshi 2004; Foster and Rosenzweig 1995); they are characterized by repeated interactions between households in formal and informal agricultural meetings; the action of social learning transcends the household dimension in favor of a more communitarian perspective. In the constant exchange between 
learning from the ancestors and learning from peers, the latter becomes more prominent when the environment is harder to interpret, as it is indeed the case of marginal areas where environmental conditions (including soil) are highly volatile (Stone 2016); this elucidates the prominent role of social learning in explaining part of the variability within the soil management ability of the households. Multiple are the possible argumentations on the emerging of the vicious cycle of social learning, but one emerges as predominant observing the marginal communities where this study is performed: a distinctive feature of the smallholder farming system in marginal areas is the wide diversity of farming households (Chikowo et al. 2014). Even at the household level, different plots might show variegated soil fertility status according to both inherent factors and different resource management strategies (Rowe et al. 2016). Social learning appears therefore detrimental, not because households collide over a good rival, but most likely because they are unaware of the enormous degree of variability in the characteristics of their soils. Social meetings centered on agricultural exchange of knowledge, being them formal or informal, gather from a minimum of 10 to a maximum of $70-80$ participants; respondents declare receiving farming advice from peers during these occasions and to frequently adopt the procedures suggested, especially if they are related to agricultural input management, being it seeds or soil. It is therefore not unlikely the fact that similar farming techniques might diffuse widely, even though they are not optimal for all the households adopting them. Mechanisms of imitation and behavioral signaling might prevail on the necessity to carefully assess the efficacy of widely spread soil management techniques.

Finally, the third dimension of knowledge juxtaposed is education, given the fact that rural practices and soil management techniques are frequently taught in schools since the early years (Chowa et al. 2013). In developing countries, formal education has recently shifted toward the embodiment of participatory curricula (Kerr et al. 2019); however, in Sub-Saharan Africa, and especially in Ethiopia, very few are the occasions in which this practice is diffuse (Morrone 2017). Therefore, education encompasses in this study a top-down dimension of learning. Results show that formal education received by the farmers plays no significant role in determining soil management ability differences. This is in accordance with evidences about the role of formal education for agricultural learning: governments in developing countries, Ethiopia in primis, spend a lot of efforts and resources in improving farming-related curricula in general schools and during training of extension workers (Weir and Knight 2000). Nonetheless, the effectiveness of this measure is still uncertain: the applied literature on this topic have found that if formal education is useful for managing a technique which already belongs in the management ability set of the farmers, it is way less effective in teaching new agricultural-related techniques or technologies (Weir and Knight 2000). Moreover, agronomic curricula in formal education systems are frequently developed based on average use cases, which by construction are not able to encompass the wide heterogeneity present among the smallholder agricultural systems.

\section{Conclusions}

This study, combining a unique dataset composed by household surveys and topsoil sample data collected from households' main fields, identifies three dimensions of knowledge and formalizes the concept of soil management ability indicator, which iconizes the soil management capacity of a farmer relatively to neighbors. Consequently, the work investigates the effect of household's farming knowledge on soil management ability gradients among smallholder farmers. It is found that home learning fosters the actuation of practices compliant with a higher smallholder farmers' performance in terms of soil management ability and soil fertility; however, when dynamics scale up at the village level, mechanisms of social learning appear to harm smallholder farmers' performances in terms of soil management ability. The third dimension of household's knowledge identified, i.e., education, appears to play no role in in preserving soil management ability.

The work purposely poses an accent on unlocking socioeconomic factors able to couple the need for increasing smallholder farmers' productivity and income with the necessity to preserve soil fertility for resilience. The results of this work advocate for a holistic inclusion of the farmers' knowledge in all the agricultural production steps, not last during the soil and resource management phases. Trends suggest that, in developing countries, current agricultural policies tend to invest extensively in decentralized and participatory actions. However, policies include farmers' knowledge only at the end of the food production process, mainly during the marketing phase. The ethnopedological microcosm of households' farming knowledge calls for a policy inclusion that should be designed in a bi-directional perspective: on one side, farmers should be empowered as agents of knowledge, given the virtuous cycle born from home learning mechanisms; on the other side, farmers should benefit from micro-based glocal trainings, which entail a global perspective and a local implementation. Despite similar pedological and environmental conditions, for enhancing soil management ability and consequently soil fertility, one-village-fits-all models are not enough.

Further works should aim at codifying the exchange of farmers' knowledge among marginal communities at a finer 
degree of specificity, in the attempt to encompass further attitudinal aspects of the household's soil management ability, such as the degree of autonomy in experimentation as well as the attitude to soil managerial changes.

Acknowledgments The authors would like to thank the Ethiopian Country Office of Alliance Bioversity - CIAT for the support during the field work. We are grateful to Dr. Girma Kassie Tesfahun, Senior Agricultural Economist at ICARDA (International Centre for Agricultural Research in the Dry Areas), and to Dr. Solomon Dawit, East Africa Program Leader of CGIAR's Research Program on Climate Change, Agriculture and Food Security (CCAFS), for their feedback and comments on the manuscript.

Code availability The code used to analyze the data and to produce figures is available in the project's GitHub repo: https://github.com/ moccelli/natsust-soil-knowledge.

Data availability The data that supports the findings of this study are available in the project's GitHub repo: https:/github.com/moccelli/ natsust-soil-knowledge.

\section{Compliance with ethical standards}

Funding This study has been funded and endorsed by the Barilla Centre for Food and Nutrition, with the BCFN!YES Award 2018. This study was possible with the contribution of CGIAR program on Water, Land and Ecosystem (WLE) which is carried out with support from the CGIAR Trust Fund and through bilateral funding agreements. For details please visit https://wle.cgiar.org/donors. The views expressed in this document cannot be taken to reflect the official opinions of these organizations.

Ethics declaration The study is not clinical and human participants are only required to answer some questions aimed at analyzing the impact that traditional knowledge has on soil management ability of smallholder farmers in marginal areas. Therefore, approval of such a specific protocol from an ethical committee is not binding under the current legal framework, as declared by the Data Protection Officer at Sant'Anna School of Advanced Studies. The researchers were committed to the Ethics Code on data processing for statistics and scientific research purposes issued by the Italian Data Protection Authority under article 20 Legislative Decree 101/ 2018

Informed consent was obtained from all individual participants included in the study.

Conflict of interest Martina Occelli has received BCFN!YES Award 2018 from the Barilla Centre for Food and Nutrition.

Alberto Mantino, Giorgio Ragaglini, Matteo Dell'Acqua, Carlo Fadda, Mario Enrico Pè, and Alessandro Nuvolari declare that they have no conflict of interest.

Authors' contribution Conceptualization: M.O, A.M, G.R, M.D., C.F, M.E.P, and A.N; Methodology: M.O, A.M, G.R., and A.N; Investigation: M.O in the field; Formal analysis: M.O, A.M, and G.R; Writing: M.O, A.M, G.R, M.D., C.F, M.E.P, and A.N; Supervision: M.E.P and A.N; Funding acquisition: M.O, M.E.P, G.R, and A.N.

Open Access This article is licensed under a Creative Commons Attribution 4.0 International License, which permits use, sharing, adaptation, distribution and reproduction in any medium or format, as long as you give appropriate credit to the original author(s) and the source, provide a link to the Creative Commons licence, and indicate if changes were made. The images or other third party material in this article are included in the article's Creative Commons licence, unless indicated otherwise in a credit line to the material. If material is not included in the article's Creative Commons licence and your intended use is not permitted by statutory regulation or exceeds the permitted use, you will need to obtain permission directly from the copyright holder. To view a copy of this licence, visit http://creativecommons.org/licenses/by/4.0/.

\section{References}

Altieri, M.A. (2002) Agroecology: the science of natural resource management for poor farmers in marginal environments. Agric Ecosyst Environ, 93(1-3): 1-24. https://doi.org/10.1016/s0167-8809(02) 00085-3

Agricultural Transformation Agency (ATA) (2013). Annual Report, Addis Ababa, Ethiopia

Balemi T, Negisho K (2012) Management of soil phosphorus and plant adaptation mechanisms to phosphorus stress for sustainable crop production: a review. J Soil Sci Plant Nutr 12:547-562. https://doi. org/10.4067/s0718-95162012005000015

Bandiera O, Rasul I (2006) Social networks and technology adoption in northern Mozambique. Econ J 116(514):869-902. https://doi.org/ 10.1111/j.1468-0297.2006.01115.x

Barrios E, Delve RJ, Bekunda M, Mowo J, Agunda J, Ramisch J, Trejo MT, Thomas RJ (2006) Indicators of soil quality: a South-South development of a methodological guide for linking local and technical knowledge. Geoderma 135:248-259. https://doi.org/10.1016/ j.geoderma.2005.12.007

Barrios E, Trejo MT (2003) Implications of local soil knowledge for integrated soil management in Latin America. Geoderma 111:217231. https://doi.org/10.1016/S0016-7061(02)00265-3

Barrera-Bassols N, Zinck JA (2003) Ethnopedology: a worldwide view on the soil knowledge of local people. Geoderma 111(34):171-195. https://doi.org/10.1016/s0016-7061(02)00263-x

Berhane G, Ragasa C, Abate GT, Assefa TW (2018) The state of agricultural extension services in Ethiopia and their contribution to agricultural productivity. International Food Policy Research Institute (IFPRI), Washington DC. https://doi.org/10.2499/1037800843

Blauert J, Zadek S (1998) Mediating sustainability. Kumarian Press, Connecticut, United States

Caretta MA (2015) Managing variability and scarcity. An analysis of Engaruka: a Maasai smallholder irrigation farming community. Agric Water Manag 159:318-330. https://doi.org/10.1016/j.agwat. 2015.05.015

Chikowo R, Zingore S, Snapp S, Johnston A (2014) Farm typologies, soil fertility variability and nutrient management in smallholder farming in Sub-Saharan Africa. Nutr Cycl Agroecosyst 100(1):1-18. https:// doi.org/10.1007/s10705-014-9632-y

Conley T, Udry C (2001) Social learning through networks: the adoption of new agricultural technologies in Ghana. Am J Agric Econ 83(3): 668-673. https://doi.org/10.1111/0002-9092.00188

Crowley, E.L. (1997) Rapid data collection using wealth ranking and other techniques. International Centre for Research in Agroforestry (ICRAF), Nairobi, Kenya

Dessart FJ, Barreiro-Hurlé J, van Bavel R (2019) Behavioral factors affecting the adoption of sustainable farming practices: a policyoriented review. Eur Rev Agric Econ 46(3):417-471. https://doi. org/10.1093/erae/jbz019

Flores M (1989) Velvet beans: an alternative to improve small farmers' agriculture. ILEIA Newsletter 5:8-9

Food and Agriculture Organization (FAO) of the United Nations and Intergovernmental Technical Panel on Soils (ITPS) (2015) Status of the World's Soil Resources (SWSR) - Main Report. Food and 
Agriculture Organization of the United Nations and Intergovernmental Technical Panel on Soils. Rome, Italy

Foster AD, Rosenzweig MR (1995) Learning by doing and learning from others: human capital and technical change in agriculture. J Polit Econ 103(6):1176-1209. https://doi.org/10.1086/601447

Fujisaka S, Hurtado L, Uribe R (1996) A working classification of slashand-burn agricultural systems. Agrofor Syst 34(2):151-169. https:// doi.org/10.1007/bf00148159

Furbee L (1989) A folk expert system: soils classification in the Colca Valley, Peru. Anthropol Q 62(2):83-102. https://doi.org/10.2307/ 3318128

Gerten D, Heck V, Jägermeyr J, Bodirsky BL, Fetzer I, Jalava M, Kummu M, Lucht W, Rockström J, Schaphoff S, Schellnhuber HJ (2020) Feeding ten billion people is possible within four terrestrial planetary boundaries. Nat Sustain 3(3):200-208. https://doi.org/10. 1038/s41893-019-0465-1

Hamiache, J., Bel, L., Vaudour, E. and Gilliot, J.M. (2012) Spatial stochastic modelling of topsoil organic carbon content over a cultivated peri-urban region, using soil properties, soil types and a digital elevation model, in: Digital soil assessments and beyond, B. Minasny, B.P. Malone, and A.B. McBratney, (eds), CRC Press, Balkema, the Netherlands

Jagger, P. and Pender, J. (2003) The role of trees for sustainable management of less-favored lands: the case of eucalyptus in Ethiopia. Forest Policy Econ, 5(1): 83-95. https://doi.org/10.1016/s1389-9341(01) 00078-8

Jarvie HP, Sharpley AN, Flaten D, Kleinman PJA, Jenkins A, Simmons T (2015) The pivotal role of phosphorus in a resilient water-energyfood security nexus. J Environ Qual 44(4):1049-1062. https://doi. org/10.2134/jeq2015.01.0030

Kerr RB et al (2019) Farming for change: developing a participatory curriculum on agroecology, nutrition, climate change and social equity in Malawi and Tanzania. Agric Hum Values 36(3):549566. https://doi.org/10.1007/s10460-018-09906-x

Kidane YG, Mancini C, Mengistu DK, Frascaroli E, Fadda C, Pè ME, Dell'Acqua M (2017) Genome wide association study to identify the genetic base of smallholder farmer preferences of durum wheat traits. Front Plant Sci 8:1230-1241. https://doi.org/10.3389/fpls. 2017.01230

Laekemariam F, Kibret K, Shiferaw H (2018) Potassium (K)-to-magnesium $(\mathrm{Mg})$ ratio, its spatial variability and implications to potential Mg-induced K deficiency in nitisols of southern Ethiopia. Agric Food Security 7(1):13. https://doi.org/10.1186/s40066-018-0165-5

Lombardo L, Saia S, Schillaci C, Mai PM, Huser R (2018) Modeling soil organic carbon with quantile regression: dissecting predictors' effects on carbon stocks. Geoderma 318:148-159. https://doi.org/10. 1016/j.geoderma.2017.12.011

Mairura FS, Mugendi DN, Mwanje JI, Ramisch JJ, Mbugua PK, Chianu JN (2007) Integrating scientific and farmers' evaluation of soil quality indicators in Central Kenya. Geoderma 139(1-2):134-143. https://doi.org/10.1016/j.geoderma.2007.01.019

Morrone, V. (2017) Outreach for rural innovation. Agricultural systems: Agroecology and rural innovation for development. Snapp, Sieglinde S. and Barry Pound (eds). 2 ed., 407-439, Cambridge, UK

Mowo JG, Janssen BH, Oenema O, German LA, Mrema JP, Shemdoe RS (2006) Soil fertility evaluation and management by smallholder farmer communities in northern Tanzania. Agric Ecosyst Environ 116(1-2):47-59. https://doi.org/10.1016/j.agee.2006.03.021

Munshi K (2004) Social learning in a heterogeneous population: technology diffusion in the Indian Green Revolution. J Dev Econ 73(1): 185-213. https://doi.org/10.1016/j.jdeveco.2003.03.003

Negera CU, Bekele AE, Wondimagegnehu BA (2019) The role of informal local institutions in food security of rural households in southwest Ethiopia. Int J Commun Soc Dev 1(2):124-144. https://doi. org/10.1177/2516602619853419
Nkonya, E., Mirzabaev, A. and Von Braun, J. eds. (2016) Economics of land degradation and improvement: a global assessment for sustainable development. Springer International Publishing, Cham, Switzerland https://doi.org/10.1007/978-3-319-19168-3

Noltze M, Schwarze S, Qaim M (2012) Understanding the adoption of system technologies in smallholder agriculture: the system of rice intensification (SRI) in Timor Leste. Agric Syst 108:64-73. https:// doi.org/10.1016/j.agsy.2012.01.003

Öborn I et al (2005) Critical aspects of potassium management in agricultural systems. Soil Use Manag 21(1):102-112. https://doi.org/10. 1111/j.1475-2743.2005.tb00414.x

Ojiem, J.O., De Ridder, N., Vanlauwe, B. and Giller, K.E. (2006) Socioecological niche: a conceptual framework for integration of legumes in smallholder farming systems. International Journal of Agricultural Sustainability, 4(1): 79:93. https://doi.org/10.1080/ 14735903.2006.9686011

Pawluk RR, Sandor JA, Tabor JA (1992) The role of indigenous soil knowledge in agricultural development. J Soil Water Conserv 47: 298-302

Richelle L, Visser M, Bock L, Walpole P, Mialhe F, Colinet G, Dendoncker N (2018) Looking for a dialogue between farmers and scientific soil knowledge: learnings from an ethnogeomorphopedological study in a Philippine's upland village. Agroecol Sustain Food Syst 42:2-27. https://doi.org/10.1080/ 21683565.2017.1322661

Sanchez PA (2002) Ecology: soil fertility and hunger in Africa. Science 295(5562):2019-2020. https://doi.org/10.1126/science.1065256

Selby B (1965) The index of dispersion as a test statistic. Biometrika 52(3-4):627-629. https://doi.org/10.1093/biomet/52.3-4.627

Stone GD (2016) Towards a general theory of agricultural knowledge production: environmental, social, and didactic learning. J Culture Agric 38(1):5-17. https://doi.org/10.1111/cuag.12061

Tabor J (1990) Ethnopedology: using indigenous knowledge to classify soils. Arid Lands Newslett 30:19-28

Tittonell P, Vanlauwe B, Leffelaar PA, Rowe EC, Giller KE (2005) Exploring diversity in soil fertility management of smallholder farms in western Kenya: I. Heterogeneity at region and farm scale. Agric Ecosyst Environ 110(3-4):149-165. https://doi.org/10.1016/ j.agee.2005.04.001

Tittonell P, Giller KE (2013) When yield gaps are poverty traps: the paradigm of ecological intensification in African smallholder agriculture. Field Crop Res 143:76-90. https://doi.org/10.1016/j.fcr. 2012.10.007

Tripathi DK, Singh VP, Chauhan DK, Prasad SM, Dubey NK (2014) Role of macronutrients in plant growth and acclimation: recent advances and future prospective. In: Improvement of crops in the era of climatic changes. Springer, New York, USA, pp 197-216

USDA-NRCS (1996) Soil quality resource concerns: compaction. USDA-NRCS Soil Quality Institute, Ames, IA

Vanlauwe B, Tittonell P, Mukalama J (2007) Within-farm soil fertility gradients affect response of maize to fertiliser application in western Kenya. In: Advances in integrated soil fertility management in subSaharan Africa: challenges and opportunities. Springer, Dordrecht, pp 121-132

Vanlauwe B, Descheemaeker K, Giller KE, Huising J, Merckx R, Nziguheba G, Wendt J, Zingore S (2015) Integrated soil fertility management in sub-Saharan Africa: unravelling local adaptation. Soil 1(1):491-508. https://doi.org/10.5194/soil-1-491-2015

Waters CN, Zalasiewicz J, Summerhayes C, Barnosky AD, Poirier C, Ga uszka A, Cearreta A, Edgeworth M, Ellis EC, Ellis M, Jeandel C, Leinfelder R, McNeill JR, Richter D, Steffen W, Syvitski J, Vidas D, Wagreich M, Williams M, Zhisheng A, Grinevald J, Odada E, Oreskes N, Wolfe AP (2016) The Anthropocene is functionally and stratigraphically distinct from the Holocene. Science 351(6269): 2622. https://doi.org/10.1126/science.aad2622 
Weir S, Knight J (2000) Adoption and diffusion of agricultural innovations in Ethiopia: the role of education. University of Oxford, Oxford, CSAE

Winkelmann R, Zimmermann KF (1994) Count data models for demographic data. Math Popul Stud 4(3):205-221. https://doi.org/10. 1080/08898489409525374
Yaalon DH, Berkowicz S (1997) History of soil science: international perspectives. Catena Verlag, Reiskirchen

Publisher's note Springer Nature remains neutral with regard to jurisdictional claims in published maps and institutional affiliations. 